\title{
A Comparative Analysis of Productivity among Organic and Non-Organic farms in the West Mamprusi District of Ghana
}

\author{
Yakubu B. Issaka ${ }^{1, *}$, Moses Antwi ${ }^{2,+}$ and Gladys Tawia ${ }^{2,+}$ \\ 1 Department of Agribusiness Management and Finance, Faculty of Agribusiness and Communication \\ Sciences, University for Development Studies, Tamale, TL 1350 NR, Ghana \\ 2 Department of Agricultural Economics and Extension, Faculty of Agriculture, University for Development \\ Studies, Tamale, TL 1350 NR, Ghana; antwi2moses@yahoo.com (M.A.); galdyst@yahoo.com (G.T.) \\ * Correspondence: yakubu_issaka@uds.edu.gh; Tel.: +233-242-273-410 \\ + These authors contributed equally to this work.
}

Academic Editors: Robert Gallagher and Les Copeland

Received: 25 August 2015; Accepted: 22 January 2016; Published: 30 March 2016

\begin{abstract}
The study was conducted in organic and conventional crop farms in the West Mamprusi District of the Northern Region of Ghana. The key issue the study sought to determine was whether there are productivity differences among organic and conventional crop farms and what factors account for these differences. The results indeed revealed that there are productivity differences among organic and conventional crop farms. However, both had negative total factor productivity growth, largely accounted for by a negative technical change over the period considered. The technical efficiency change, however, was positive for both but much higher for organic farms than conventional farms. More importantly, the study revealed that the type of agriculture practiced by farmers is not the most critical problem confronting farmers as indicated by the negative total productivity growth for both. Major constraints confronting farmers that need to be addressed include better organization on the farmers' front, improved access to extension and improved access to farm inputs. These challenges notwithstanding, the study revealed that organic agriculture has the potential, in the long run, to achieve much more progress in total factor productivity, compared to conventional agriculture, if the right conditions exist for its uptake and optimal application.
\end{abstract}

Keywords: organic; conventional; productivity; agriculture; efficiency; technical change

\section{Introduction}

Agriculture plays a significant role in Ghana's economy, contributing about 39\% to Ghana's Gross Domestic Product [1]. Agriculture and related employment together account for more than half of the population, the majority of whom are rural. Smallholder (mostly rural) farms dominate agricultural production in Ghana. It is therefore expected that any significant growth in the agricultural sector will boost the rural economy, in particular, and will impact meaningfully on the wider economy. In view of this, productivity increases, through efficient use of existing technology and resources, must be accorded all the seriousness that they deserve in the face of worsening climatic conditions, poor accessibility to inputs by smallholder farmers and environmental degradation that has become the bane of agriculture in Sub-Saharan Africa [2].

Aggregate productivity is the amount of output obtained from given levels of inputs in an economy or sector of the economy [3]. It is obvious that output increases in agriculture by way of spatial expansion, as has been the case in the past, is no longer sustainable due to population pressure. In Ghana, fallow periods have become shorter due to increased population pressure. Consequently, 
farmers are compelled to intensify cultivation with many farmers increasingly cultivating marginal lands amidst difficulty in accessing the required inputs to support the practice. The undesirable consequences include extensive land degradation, impoverished soils and, inevitably, a worsening food security situation for many. In developing countries outside Africa, $50 \%$ to $70 \%$ of the increase in crop yield from the mid-1960s onwards has been attributed to unprecedented use of inorganic fertilizers [4] under heavy subsidy, as was the case during the green revolution. Since then, the use of chemical fertilizers has been considered a major driver of increased crop yields in Africa and other less developed countries where inorganic chemical fertilizers are considered to be complementary to other external inputs of production such as improved seed and better water control in the attainment of high crop yields [5]. This, however, has proved unsustainable due to the high cost of external inputs and the inability of governments and donors to continue subsidizing agricultural inputs. A major contributor to food insecurity is poverty, which renders large sections of the global population incapable of gaining access to adequate productive resources for food production. For large numbers of small-scale subsistence farmers all over the world, a lack of productive resources also implies a lack of financial means to acquire food, which worsens their precarious food security situation.

Various attempts have been made to either reduce or solve this problem [6], including the introduction of the modern organic system of farming, which requires minimal application of external inputs. Organic farming is a system of agriculture that uses environmentally sound inputs to grow crops and raise livestock that are free from most synthetic pesticides, growth hormones and antibiotics [7]. Organic agriculture relies on natural processes that benefit rather than harm the environment, such as the use of synthetic inputs in an innovative employment of science and tradition to support natural systems [8]. As in most African countries, the organic agricultural sector in Ghana is still relatively underdeveloped, accounting for only $0.2 \%$ of total agricultural land [9] but with a huge potential for expansion. While the contribution of organic agriculture to ecological sustainability cannot be doubted, the question needs to be asked whether the same can be said about its contribution to food security in Africa and other less developed of the world. For a region that is still grappling with the problem of food insecurity, this question is critical going into the future [10]. For developing countries like Africa, the concern with organic agriculture should first be whether it will be economically competitive, compared to conventional agriculture, as an option for addressing food security. Thus, productivity of organic agriculture compared to that of conventional agriculture, as would be expected, has taken central stage in the debate about organic agriculture and food security. Contributing to the on-going debate, some authors [11] undertook a comparative analysis of yield data of organic and conventional agriculture comprising 43 countries globally. They discovered that, on average, yields under organic agriculture were about $20 \%$ lower than those from conventional agriculture but with wide variation among regions and crops. They admit, however, that the poor representation of Africa in the data set could have led to some bias. Others have estimated yields achieved under agriculture of as much as $180 \%$ of that achieved under conventional agriculture for developing countries [12]. More importantly, and of interest to northern Ghana, is the argument that under adverse weather conditions and low input situations, organic agriculture can achieve much higher yields than those of conventional agriculture $[13,14]$. These results are interesting for the study area where adverse weather conditions, exacerbated by climate change and poor access to inputs, have constrained agricultural productivity.

The West Mamprusi District has seen a particularly strong effort by Non-Governmental Organisations (NGOs) to promote organic farming for the past 20 years. While it is admittedly important to seek to accelerate agricultural production by introducing new technologies, it is arguably also important to consider whether the necessary conditions exist for the optimal use of existing technologies by farmers. This study examines sources of productivity differences among smallholder organic and conventional farmers by means of the non-parametric malmquist index approach. Unlike others, the malmquist total factor productivity indices disaggregate productivity growth into technical change, related to technology, and the less obvious productivity growth due to efficient change. 
This allows for taking into consideration the potential efficiency enhancing factors contributing to productivity growth.

\section{Experimental Section}

\subsection{The study Area}

The study was conducted in the West Mamprusi district of the Northern Region of Ghana. The district is located between longitudes $0^{\circ} 35^{\prime} \mathrm{W}$ and $1^{\circ} 45^{\prime} \mathrm{W}$ and latitudes $9^{\circ} 55^{\prime} \mathrm{N}$ and $10^{\circ} 35^{\prime} \mathrm{N}$. The area experiences a single rainfall pattern from May-June to September-October. Mean annual rainfall ranges between $950 \mathrm{~mm}-1200 \mathrm{~mm}$. The natural vegetation of the area is Guinea Savannah Woodland dominated by grassland and fire resistant trees like Vitellaria spp., Parkia spp. and Adonsonia spp. Smallholder agriculture is the mainstay of the local economy. Production of food crops such as maize, millet, sorghum, groundnuts and the rearing of livestock constitute the main agricultural activity in the district. Cowpea, bambara, soya, rice, pepper and cotton are minor crops. Farmers generally practice mixed farming in the area as most farmers also rear livestock. However, crops like cotton are cultivated under mono-cropping. Family labour is the main source of labour for farmers. Hired labour is employed only when family labour is insufficient during critical stages of production such as planting and harvesting. Common inputs used by organic farmers include compost, organic mulch and farmyard manure.

\subsection{Method of Data Collection}

Data were collected mainly via a semi-structured questionnaire. Additional qualitative data were collected via Participatory Rural Appraisal (PRA) tools including focus group discussions, key informant interviews and personal observation for the purpose of triangulation. Respondents were selected from eight farming communities in the district where organic farming has been promoted by local NGOs among local farmers for, at least, the past 15 years. Correspondingly, conventional farmers were selected from other communities where organic agriculture is not practiced. The study used the variable total crop yield as the output variable for each of 40 organic and conventional farmers with a total sample of 80 farmers. Data were collected over the 2011-2012 and 2012-2013 farming seasons.

\subsection{Method of Data Analysis}

Productivity differences were determined on the basis of the non-parametric malmquist total factor productivity (TFP) for organic and conventional farms. TFP calculates agricultural productivity of an individual production unit by comparing an index of agricultural input to an index of outputs. More importantly, TFP is further disintegrated into technical and efficiency changes that enable an understanding of factors that contributed to productivity changes. Data Envelopment Analysis (DEA) is the main analytical tool employed in this study as illustrated below. The Malmquist index is defined by way of distance functions. The DEA uses linear programming with data on the input and output quantities of a group of entities, in this case farms, to construct a linear piece-wise frontier surface over data points. An output oriented DEA model with constant returns to scale (CRS) is assumed, believing that it makes sense that in measuring agricultural productivity, a given level of output is maximized from a given level of inputs rather than the converse. This assumption is particularly important in smallholder agriculture characterized by resource constraints. In this study, therefore, agricultural productivity is explained by way of specific inputs to output growth of organic and conventional farms.

The DEA problem is as illustrated for five farms A, B, C, D and E in Figure 1 below. 


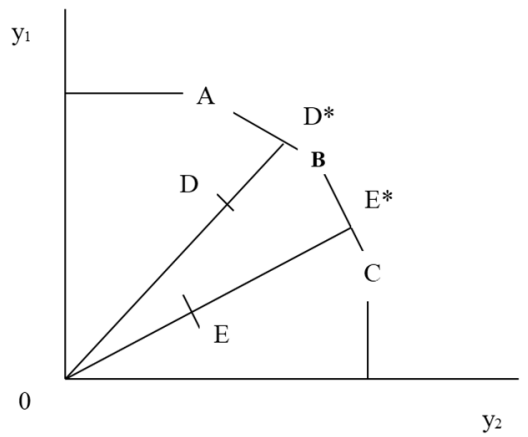

Figure 1. Output oriented data envelop analysis. Farms A, B and C are efficient and therefore define the production frontier for this group of five farms. On the other hand, countries D and $\mathrm{E}$ are inefficient as their output is below the optimum as defined by the production frontier. The technical efficiency score for farm $D(T E D)$ and $E(T E E)$ are as defined below: $T E D=O D / O D^{*}$ and $T E E=O E / E^{* *}$ with $\mathrm{A}$ and $\mathrm{B}$ and $\mathrm{B}$ and $\mathrm{C}$ as their peers, respectively, which means that $\mathrm{D}$ and $\mathrm{E}$ are benchmarked against $\mathrm{A}$ and $B$ and $B$ and $C$, respectively.

\subsection{Malmquist TFP Indices}

The DEA model applied to this study is the Malmquist-DEA index describing a multi-input and multi-output production technology distance function. The malmquist total factor productivity index can be decomposed into two components, namely a technical efficiency change and a technical change [15]. The technical efficiency change tells us whether a particular farmer is moving closer to the frontier or further away from the frontier. Technical change also refers to a shift of the frontier. To illustrate this, suppose a production technology of output set $\mathrm{P}(\mathrm{x})$ defined as follows:

$$
P(x)=\{y: x \text { can produce } y\}
$$

The output distance function at the initial period $s$ is defined as:

$$
d s(x, y)=\operatorname{Min}\left\{\theta: \frac{y}{\theta} \in P(x)\right.
$$

The distance function $d s(x, y)$ will assume a value less or equal to 1 if the output $y$ is a member of the feasible production set, $P(x)$. In addiiton, the distance function will assume a value of unity if $y$ is located on the outer boundary of the feasible production set, and takes a value greater than 1 if $\mathrm{y}$ is located outside the feasible production set. Following Equation (2) above, when $\theta$ is minimized, $\theta / y$ maximized. The output orientated malmquist TFP change between period $s$ (the base period) and period $t$ is given by:

$$
m\left(x^{t}, y^{t}, x^{s}, y^{s}\right)=\left(\frac{d^{s}\left(x^{t}, y^{t}\right)}{d^{s}\left(x^{s}, y^{s}\right)} \times \frac{d^{t}\left(x^{t}, y^{t}\right)}{d^{t}\left(x^{s}, y^{s}\right)}\right)^{1 / 2}
$$

where $d^{s}\left(x^{t}, y^{t}\right)$ is the distance from the period $t$ with respect to the period s technology. $m>1$ indicates positive TFP growth from period $\mathrm{s}$ to period $\mathrm{t}$ while $m<1$ indicates a decline in TFP.

The expression in Equation (3) is subsequently decomposed to represent the technical efficiency change between the period $\mathrm{s}$ and $\mathrm{t}$ and the technical change between periods $x^{s}$ and $x^{t}$ as follows:

$$
\begin{gathered}
\text { Efficiency change }=\frac{d^{t}\left(x^{t}, y^{t}\right)}{d^{s}\left(x^{s}, y^{s}\right)} \\
\text { Technical change }=\left(\frac{d^{s}\left(x^{t}, y^{t}\right)}{d^{t}\left(x^{t}, y^{t}\right)} \times \frac{d^{t}\left(x^{s}, y^{s}\right)}{d^{t}\left(x^{s}, y^{s}\right)}\right)^{1 / 2}
\end{gathered}
$$




\subsection{The Data}

Six (6) inputs each were considered under organic and conventional agriculture while the output consisted of the aggregated output of the major crops cultivated.

\subsection{Output Series}

The output variables considered are maize, millet, sorghum and groundnuts as these constitute the major crops cultivated in the area. This was aggregated from the various holdings of a farmer for organic and conventional plots.

\subsection{Input Series}

Land: This variable consists of the total acreage of all land under cultivation aggregated for all the individual holdings of a farmer.

Farm Labour: The main source of labour for farmers in the study area is family labour. Thus, the number of economically active members of a farmer's household was assumed to represent the labour force.

Seed: The total quantity of improved seed utilized by a farmer was estimated in metric tons per farm and aggregated for all the farm holdings of a farmer.

Fertilizer: The total quantity of fertilizer utilized by a farmer was estimated in metric tons per farm and aggregated for all the farm holdings of a farmer.

Compost: The total quantity of compost used was estimated in metric tons per individual farm and aggregated for all the holders of a farmer.

Tractor: Since most farmers do not own tractors, access to tractor services is represented by the number of times a farmer had timely access to tractor services during the past 10 farming seasons.

Extension: Access to extension was determined by a simple count of the number of times (frequency) a farmer receives visits from extension agents.

\section{Results and Discussion}

\subsection{Demographic Characteristics of the Respondents}

\subsubsection{Age and the Decision to Engage in Organic Agriculture}

The age distribution of respondents is illustrated in Figure 2. Overall, 58.8\% of the respondents were within the age group of $20-40$ years and these accounted for $26.3 \%$ and $32.5 \%$ of organic and conventional farmers, respectively. A total of $37.4 \%$ of all farmers were within 41-61 years of age, making up, respectively, $21 \%$ of organic and $16.2 \%$ of conventional farmers. About 4 percent of respondents were 62 years, accounting for $2.5 \%$ and $1.3 \%$ organic and conventional farmers, respectively. See Figure 1 below. Generally, a higher percentage of the active population (20-40) constitutes the labour force. However, comparatively more farmers in this age group are practicing conventional farming. On the other hand, relatively more farmers within the older generations are practicing organic agriculture. The reason is not immediately apparent. However, it points to the likelihood that the younger generation is less interested in adopting organic farming.

\subsubsection{Gender and the Decision to Engage in Organic Agriculture}

The majority (75\%) of both organic and conventional farmers were males. This is probably due to the fact that males control access to land in the area. A woman can only have access to land in her family holding if she is divorced or upon the death of a husband to enable her to feed her children. Besides, married women are expected to help their husbands on the family land. Therefore, most women who farm only do so to help their husbands and only a few have farms of their own. Consequently, the decision in the household regarding which type of agriculture to engage in is dominated by males. Women who were found to be actively engaged in any form of farming were household heads. 


\section{Age Distribution of Farmers}

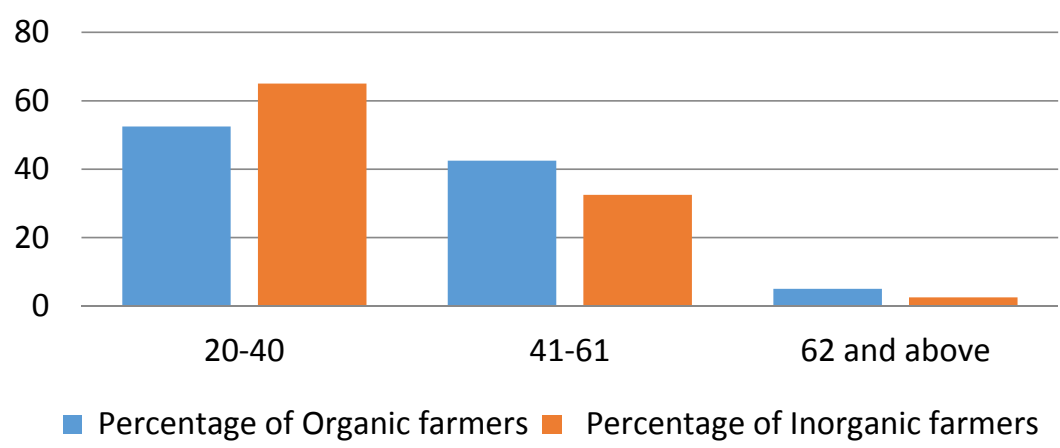

Figure 2. Age distribution of farmers.

\subsubsection{Educational Status and the Decision to Engage in Organic Agriculture}

Figure 3 presents the educational status for both organic and conventional farmers. The majority of farmers accounting for $72.5 \%$ of organic and $67.5 \%$ of conventional farmers have not received any form of formal education. Education has been demonstrated to have a positive influence on the adoption of technology by farmers [13]. This is perhaps the reason why more organic farmers have attained secondary education compared with conventional farmers.

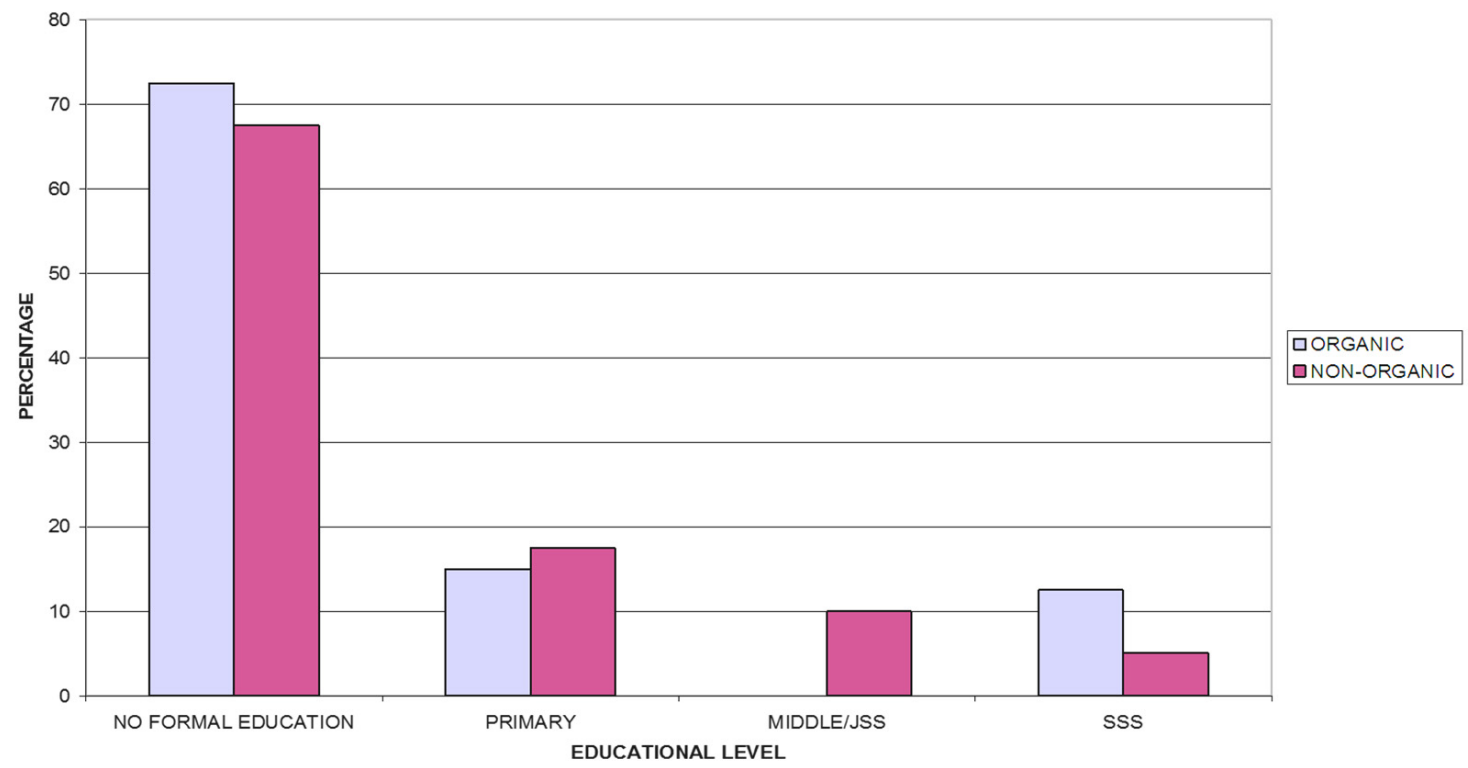

Figure 3. Educational status of respondents.

\subsubsection{Overview of the Results from the Malmquist Indices}

The aim of the study is to determine whether there is a productivity difference among organic and conventional farms. It is, however, important to acknowledge that both organic and conventional farms achieved some productivity growth over the 2-year period albeit minimal gains. The results suggested that productivity growth between the two periods is low. A TFP growth of 0.609 and 0.532 was recorded for conventional and organic farms, respectively, over the entire period of 2011-2012. However, there was a slight increase in the annual growth rate of 0.629 and 0.535 for conventional and organic farms, respectively, for the period 2012-2013. The higher progress made among conventional farms appears to be related to the introduction of the government's fertilizer subsidy programme. 
This is plausible given that the high cost of fertilizer had posed a major constraint to improved farm productivity prior to the introduction of the fertilizer subsidy.

Table 1 above reports the mean productivity change of all the farms for the 2011-2012 and 2012-2013 cropping seasons for both organic and conventional farms in the study area. The malmquist indices indicate that there is indeed a productivity difference among organic and conventional farms. Although TFP growth was negative for both organic (0.648) and conventional (0.663) farms over the entire period, conventional farms recorded a slightly lower rate of reduction of $33.7 \%$ compared to their organic counterparts, which was $35.2 \%$. Considering the components individually, the technical efficiency change recorded a positive growth overall. Organic farms, however, recorded a higher technical efficiency change of $7.2 \%$ compared to $1.8 \%$ for their conventional counterparts. Technical change, on the other hand, recorded a negative change of 0.651 (34.9\% decrease) and 0.605 (39.5\% decrease) for conventional and organic farms, respectively. Thus, although organic farms are more efficient in input use, they recorded a lower TFP due to a lower technical change. A closer look at the performance of individual farms reveals that $50 \%$ of farms under both systems were technically efficient over the period under consideration. On the other hand, $27.5 \%$ and $20 \%$ of organic and conventional farms, respectively, made progress in technical efficiency while $22.5 \%$ and $30 \%$ of organic and conventional farms, respectively, actually recorded a decline in technical efficiency. Two farms each under organic and conventional agriculture recorded technical progress while the rest declined.

Table 1. Productivity indices.

\begin{tabular}{lcc}
\hline & Organic & Conventional \\
\hline Efficiency Change (EFFCH) & 1.072 & 1.018 \\
Technical Change (TECHCH) & 0.605 & 0.651 \\
Total Factor Productivity Change (TFPCH) & 0.648 & 0.663 \\
\hline
\end{tabular}

\subsection{Discussion}

The results from the study appears to point to findings by others (12), i.e., that organic agriculture results in much higher productivity compared to conventional agriculture in low input and arid conditions as is the case in the West Mamprusi district of Ghana. This is because a closer look at the results reveal that the two organic farms that achieved progress in TFP recorded much higher TFP indices $(33.2 \%$ and $92.3 \%)$ compared to that achieved under conventional agriculture $(2.5 \%, 11.1 \%$, and $16.6 \%)$.

The poor performance of technical change points to the fact that the practice of both conventional and organic agricultural are not optimal as the study revealed. One common limitation that was observed across all farms is limited access to formal extension services by farmers. Access to and implementation of improved technology by farmers in Ghana is generally constrained by inadequate access to extension services $[16,17]$. The poor access to extension services by farmers is due to the disproportionately higher farmer-extension ratio and high illiteracy rates among farmers as reported [18]. Thus, farmers do not optimize the use of both organic and conventional agricultural technologies due to inadequate technical support. Poor access to inputs, for both organic and conventional farmers, appear to have contributed to the poor performance of technical change. The study revealed that timely access to fertilizer and cost were major problems confronting conventional farmers despite the introduction of the fertilizer subsidy. Thus, in some cases, farmers indicated applying less than the recommended quantities of fertilizer. Access to fertilizer by conventional farmers in the West Mamprusi district is critical for improved productivity due to intensification over a long period of time that has seen levels of soil fertility drop significantly. On the other hand, organic farmers are unable to obtain adequate quantities of organic material for compost preparation, which is the main organic input used. Additionally, the tedious and labour intensive nature of compost preparation has made it difficult for farmers to produce adequate quantities of compost. 
Organic farmers were better organised and networked than conventional farmers as they are organised into farmer-based organisations and engage in efficiency enhancing practices such as "Group farming" that enable groups of farmers to provide labour to each other's farmers in turn. The group farming concept was initiated by Zasilari Ecological Farms Project (ZEFP) and the Chera Biisi Fari Project (CBFP), two NGOs that are actively supporting organic farmers in the West Mamprusi district, among organic farmers to address labour shortages. Farmers in the various communities are organised into solidarity groups that provide labour to each other's' farms in turn. The study revealed that "group farming" in particular was much more efficiency enhancing since timely access to labour is highly constrained during critical stages of the farm, such as weeding, planting and harvesting. Therefore, providing labour, in turn, to each other's farmers ensures that group members had timely access to labour at a relatively lower cost than other farmers.

Additionally, solidarity groups provide avenues for easy dissemination and diffusion of extension information. During their monthly meetings, farmers interact with the staff of these NGOs and among themselves, sharing information, experiences and seeking advice on their challenges. Therefore, organic farms are less constrained by the generally poor access to extension services and information faced by other farmers as regular meetings of farmers and NGO staff ensures that there is regular access to technical support by farmers. The key lesson in this regard is that frequent interaction among farmers makes them more efficient even if they do not receive professional extension services. The study has also demonstrated that vibrant farmer-based organisations can contribute to improved productivity by collectively addressing production constraints.

Constraints to organic and non-organic farmers in the West Mamprusi District of Ghana: the major constraints confronting organic and non-organic farmers in the West Mamprusi district of Ghana are summarised in Table 2 below.

Table 2. Constraints.

\begin{tabular}{ll}
\hline Constraints of Organic Farming & Constraints of Conventional Farming \\
\hline $\begin{array}{l}\text { The labour intensive nature of compost } \\
\text { preparation has resulted in smaller organic } \\
\text { farm sizes }\end{array}$ & $\begin{array}{l}\text { High cost of inorganic fertilizer and pesticides } \\
\text { makes it difficult for farmers to apply the } \\
\text { recommended amounts of inputs }\end{array}$ \\
\hline $\begin{array}{l}\text { Lack of appropriate implements and tools } \\
\text { makes compost preparation tedious }\end{array}$ & $\begin{array}{l}\text { Poor access to credit makes it difficult to expand } \\
\text { production }\end{array}$ \\
\hline $\begin{array}{l}\text { Poor access to credit makes it difficult to } \\
\text { expand production }\end{array}$ & $\begin{array}{l}\text { Inadequate extension support makes it difficult to } \\
\text { make efficient use of inputs }\end{array}$ \\
\hline $\begin{array}{l}\text { Organic products are not differentiated from } \\
\text { conventional farm products making it difficult } \\
\text { for organic farmers to earn more from the extra } \\
\text { effort required under organic production }\end{array}$ & $\begin{array}{l}\text { Inaccessible farm machinery for land preparation } \\
\text { results in a high cost of ploughing, further } \\
\text { constraining farm expansion }\end{array}$ \\
\hline
\end{tabular}

\section{Conclusions}

For the present study, the conclusions are as follows: The study points to the fact that potentially, over the long term, organic farms could prove to be more productive than conventional farms since organic farms are more technically efficient and can achieve superior technical gains if practiced according to recommended practice. A major drawback to achieving appreciable progress in technical change is the fact that very limited organic options are implemented by farmers. The results from the malmquist indices show a poor performance of TFP with respect to agricultural productivity in both organic and conventional farming systems as a result of overall lower contribution of technological progress. This is not unexpected as access to improved technology, generally, is a challenge in Ghanaian agriculture. One of the constraints farmers face in the study area is inadequate access to extension services. This limits the implementation of technology even if it is available. Farmers still depend on traditional crop varieties instead of new and improved varieties of crops that could be more productive. The fact that organic farmers have more access to technical support from NGOs and are organized 
into solidarity groups, which facilitates interactions and exchange of ideas, possibly accounts for the higher technical efficiency recorded among organic farms compared with conventional farms. Technical efficiency change among organic farms has largely remained stable over time compared to conventional farms. This is not surprising since support from the two NGOs promoting organic agriculture in the study area has been consistent and therefore, the inadequacies in the extension system are felt less by organic farmers. The adoption of organic agriculture has been very slow and much more common among older farmers. In introducing technology it is important to consider contextual factors that are likely to impede adoption. In the case of organic agriculture in the communities studied, farmers complained of the tedious and labour intensive nature of organic agricultural practices, mainly the way of preparation and use of compost. This takes considerable time and effort by farmers especially during the rainy season when labour is inadequate. Consequently, it is common to observe situations where a farmer practiced conventional agriculture alongside organic agriculture in order to ensure that the household had food security.

Practicing organic or conventional systems of farming is not the most important constraint confronting farmers as far as agricultural productivity growth in the West Mamprusi district is concerned. This is demonstrated by the low TFP growth for both organic and conventional farms in the study area. Ensuring that farmers have adequate access to inputs, in both types of agriculture, should be addressed with much more urgency than it is at the moment. In the face of severe lack of access by farmers to extension services, Farmers-based Organisations (FBOs) could serve as important avenues through which this could be addressed. The study revealed that organic farmers are not practicing organic farming in the true sense as some farmers sometimes used inorganic pesticides, citing lack of access to organic alternatives. In this case, access to commercial organic inputs at affordable prices, ensured by inclusion in the government's fertilizer subsidy programme, could accelerate the adoption of organic agriculture. For effective promotion of organic agriculture, there is the need for farmers to be provided the necessary incentives through price discrimination in favour of organic products. This requires promotion of organic food as a healthier alternative to conventional food.

Acknowledgments: We wish to acknowledge the support received from all the farmers who participated in this research. Furthermore, we appreciate the invaluable support provided to us during the study by the staff of Zasilari Ecological Farm Project (ZEFP), especially David Agongo, Sampana James and Yidana Toli Kate.

Author Contributions: Yakubu I. Issaka conceptualized the study, provided technical guidance during the study and undertook the final write up of the paper. Moses Antwi and Gladys Tawia both undertook data collection and initial analysis.

Conflicts of Interest: The authors declare no conflict of interest

\section{References}

1. Ministry of Food and Agriculture. Medium Term Agricultural Sector Investment Plan (METASIP). Ministry of Food and Agriculture: Accra, Ghana, 2011.

2. Baah, O. Technology Policy and Practice in Africa; Ogbu, Osita M., Oyeyinka, Banji O., Mlawa, Hasa M., Eds.; The International Development Research Centre (IDRC): Ottawa, ON, Canada, 2006.

3. Fulginity, L.E.; Perrin, R.K. Productivity in LDC Agriculture: Non-parametric Malmquist Measures; Center for Agricultural and Rural Development: Ames, IA, USA, 1994.

4. Havlin, J.L.; Beaton, J.D.; Tisdala, S.L; Nelson, W.L. Soil Fertility and Fertilizers, 7th ed.; Prentice Hall: Englewood Cliffs, NJ, USA, 2000.

5. Follet, R.H.; Murphy, L.S.; Donahue, R.L. Fertilizers and Soil Amendments; Prentice Hall: Englewood Cliffs, NJ, USA, 1981.

6. Yadav, A.K.; Chaudhary, S.R.; Talukdar, N.C. Biotechnology in Sustainable and Organic Farming; Shree Publisher and Distribution: New Delhi, India, 2004.

7. Harris, J.M. Basic Principles of Sustainable Development; Global Development and Environment Institute: Medford, MA, USA, 2000.

8. IFOAM. Available online: http://www.ifoam.bio/en/organic-landmarks/definition-organic-agriculture 2005 (accessed on 20 August 2015). 
9. Research Institute of Organic Agriculture (FIBL); International Federation of Organic Agriculture Movements IFOAM. The World of Organic Agriculture: Statistics and Emerging Trends 2014; Medienhaus Plump: Rheinbreitbach, Germany, 2014.

10. Godfray, H.C.J.; Beddington, J.R.; Crute, I.R.; Haddad, L.; Lawrence, D.; Muir, J.F.; Pretty, J.; Robinson, S.; Thomas, S.M.; Toulmin, C. Food security: The challenge of feeding 9 billion people. Science 2010, 327, 812-818. [CrossRef] [PubMed]

11. De Ponti, T.; Rijk, B.; van Ittersum, M.K. The crop yield gap between organic and conventional agriculture. Agric. Syst. 2012, 108, 1-9. [CrossRef]

12. Badgley, C.; Moghtader, J.; Quintero, E.; Zakem, E.; Chappell, M.J.; Avilés-Vàzquez, K.; Samulon, A.; Perfecto, I. Organic agriculture and the global food supply. Renew. Agric. Food Syst. 2007, 22, 86-108. [CrossRef]

13. Hepperly, P.; Douds, D.; Seidel, R. The rodale farming systems trial, 1981 to 2005: Long-term analysis of organic and conventional maize and soybean cropping systems. In Long-Term Field Experiments in Organic Farming; Raupp, J., Pekrun, C., Oltmanns, M., Köpke, U., Eds.; International Society of Organic Agriculture Research (ISOFAR): Bonn, Germany, 2006; pp. 15-32.

14. Pretty, J.N.; Noble, A.D.; Bossio, D.; Dixon, J.; Hine, R.E.; Penning de Vries, F.; Morison, J. Resource-conserving agriculture increases yields in developing countries. Environ. Sci. Technol. 2006, 40, 1114-1119. [CrossRef] [PubMed]

15. Coelli, T.J.; Rao, D.S.P.; O'Donnell, C.J.; Battese, G.E. An Introduction to Efficiency and Productivity Analysis; Springer Science: New York, NY, USA, 2005.

16. Donkoh, S.; Awuni, J. Adoption of farm management practices in lowland rice production in Northern Ghana. J. Agric. Biol. Sci. 2012, 2, 84-93.

17. Akudugu, M.A.; Guo, E.; Dadzie, S.K. Adoption of modern agricultural technology by farm households in Ghana: What factors influence their decisions? J. Biol. Agric. Healthc. 2012, 2, 1-13.

18. Otieno, Z.; Okello, J.; Nyikal, R.; Mwang'ombe, A.; Clavel, D. The role of varietal traits in the adoption of improved dry land crop varieties: The case of pigeon pea in Kenya. AFJARE 2001, 6, 176-193.

(C) 2016 by the authors; licensee MDPI, Basel, Switzerland. This article is an open access article distributed under the terms and conditions of the Creative Commons by Attribution (CC-BY) license (http://creativecommons.org/licenses/by/4.0/). 